\title{
Biocide activity of microfiber mops with and without silver after contamination
}

\section{Authors}

Sonia De Lorenzi ${ }^{1}$ Letizia Romanini ${ }^{1}$ Gianfranco Finzi ${ }^{2}$ Germano Salvatorelli ${ }^{3}$

'PhD; Grant Scholar, Department of Biology and Evolution, Università di Ferrara, Italy ${ }^{2} \mathrm{MD}$; Hospital Medical Director, Hospital Management, Policlinico S.Orsola Malpigli, BolognaItaly (FINZI)

${ }^{3} \mathrm{MD}$, PhD; Full Professor of Histology, Department of Biology and Evolution, Università di Ferrara, Italy
Submitted on: 10/20/2010 Approved on: 02/10/2011

Correspondence to: Germano Salvatorelli Via L. Borsari, 46 44121, Ferrara - Italy svg@unife.it

We declare no conflict of interest.

\begin{abstract}
Objective: The purpose of the present research was to compare the residual microbial load in Solo System microfiber mops with silver and in normal microfiber mops without silver to see whether those with the silver prevent bacterial proliferation and spread more effectively during normal cleaning operations. Methods: Mops with and without silver were experimentally contaminated with suspension of Staphylococcus aureus ATCC 6538. The bioburden was evaluated by a filtering procedure according to UNI EN 1174 after contamination, after washing and after different times of impregnation in an alcohol-base detergent. Results and discussion: The results obtained lead to the conclusion that silver microfiber mop was significantly more effective in reducing bacterial load despite initial high level contamination $\left(10^{6}-10^{7} \mathrm{CFU} / 50 \mathrm{~cm}^{2}\right)$. Indeed, after low temperature washing, the bacterial load was already completely eliminated while the mop without silver still presented relatively high levels of the microorganism (approximately $10^{2} \mathrm{CFU} / 50 \mathrm{~cm}^{2}$ ) even after being soaked for 8 hours in a detergent/disinfectant.
\end{abstract}

Keywords: decontamination; surface-active agents; products with antimicrobial action; semi-colon; infection control.

[Braz J Infect Dis 2011;15(3):200-203]@Elsevier Editora Ltda.

\section{INTRODUCTION}

Nowadays, detergents are normally used for floor cleaning in the hospital environment while the use of disinfectants is reserved for wards where patients with infectious diseases, in isolation, or with multiresistant microorganisms are treated. ${ }^{1-3}$ However, the surfaces must be cleaned correctly if the procedure is to be effective and to prevent the spreading of microorganisms to uncontaminated surfaces.

Recent studies comparing the decontamination capacity of some microfiber and ultramicrofiber fabrics with that of conventional fabrics used in cleaning have shown that microfiber and ultra-microfiber fabrics remove dirt and microorganisms from surfaces more effectively., ${ }^{4,5}$ Given the high microbial load normally present, one of the drawbacks to cleaning surfaces, and in particular floors, using mops (even microfiber mops) is that the cloths - previously contaminated or contaminated during the cleaning operation - can disperse microorganisms. This can occur, for example, when a soiled cloth with a high microbial load is not effectively washed. If such contaminated cloth is reused, it will release its microbes to other surfaces. ${ }^{6}$

Today, the market offers many fabrics with silver ions bonded to the fibers and, given their antibacterial action, they offer good performance. Yeo and Jeong ${ }^{7}$ demonstrated the antibacterial effectiveness of fibers composed of polypropylene and nanoparticles of silver, proving that this effect is only seen when the fibers contain nanoparticles of silver on the surface. Another study used nylon fibers covered with silver, observing their bactericide capacity $v s$. bacteria in suspension, both in culture media containing fibers with silver in the core part and with added silver in the sheath part. In the latter case, the biocide activity was proportional to the silver ion concentration. ${ }^{8}$ Recently the Magris group (Magris S.p.a., Seriate, Bergamo, Italy) has placed on the market a new cleaning trolley (Solo System) composed of containers - 
for collection and dosing of detergent/disinfectant to be used during cleaning operations - made of molded plastic with silver filaments and microfiber mops, likewise containing silver.

Under normal cleaning procedures, after washing, the mops are set in a container of detergent/disinfectant and transported to the site ready for use; on the other hand, with the Solo System, the mop is only soaked with a set dose of detergent/disinfectant just before use. The microfiber mops with silver ions should prevent problems of cloth contamination, guaranteeing complete decontamination after normal washing. Moreover the plastic-silver containers should obviate the problem of possible detergent contamination during cleaning operations, thus guaranteeing high overall disinfection of the surfaces.

The purpose of the present research was to compare the residual microbial load in Solo System microfiber mops with silver ions and in normal microfiber mops without silver ions to see whether those with the silver ions more effectively prevent bacterial proliferation and spread during normal cleaning operations. Moreover, throughout the entire duration of the investigation, the bacterial load in the aliquot of detergent/disinfectant in the plastic-silver containers was monitored to determine the effectiveness of the overall system.

\section{MATERIALS AND METHODS}

The phases of the methodology are displayed in Figure 1.

Three Solo mops with silver and two microfiber mops without silver were impregnated with $200 \mathrm{~mL}$ of a $10^{5}$ suspension of Staphylococcus aureus ATCC 6538 and the initial bioburden was determined for each type of mop using the method outlined in UNI EN 1174 1-2-3. To this purpose, two $50 \mathrm{~cm}^{2}$ samples of each type of mop were set in bottles with screw caps (diameter: $8 \mathrm{~cm}$, height $17 \mathrm{~cm}$, total volume: $600 \mathrm{~mL}$ ) containing $300 \mathrm{~mL}$ of a $1 \%$ solution of Triptone (Incofar) in an $8.5 \%$ physiological solution with the addition of $0.1 \%$ Tween 80 (Incofar) and $60 \mathrm{~g}$ of glass beads (diameter: $3 \mathrm{~mm}$ ). Before use, the containers and their contents were sterilized in an autoclave. After agitation for $5 \mathrm{~min}$ with mechanical rotary stirrer, an aliquot was taken from the bottles and adequately diluted. This was then used to seed $9 \mathrm{~cm}$ diameter Petri dishes containing Mannitol Salt Agar (Incofar) and these dishes were incubated at $36.5 \pm 1^{\circ} \mathrm{C}$. After $24-48$ hours of incubation, the colonies developed were counted.

The remaining three mops (two Solo microfiber mops with silver and one conventional microfiber mop) were given to the hospital laundry and washed in a washer extractor. Before and after each wash, the washer extractor was

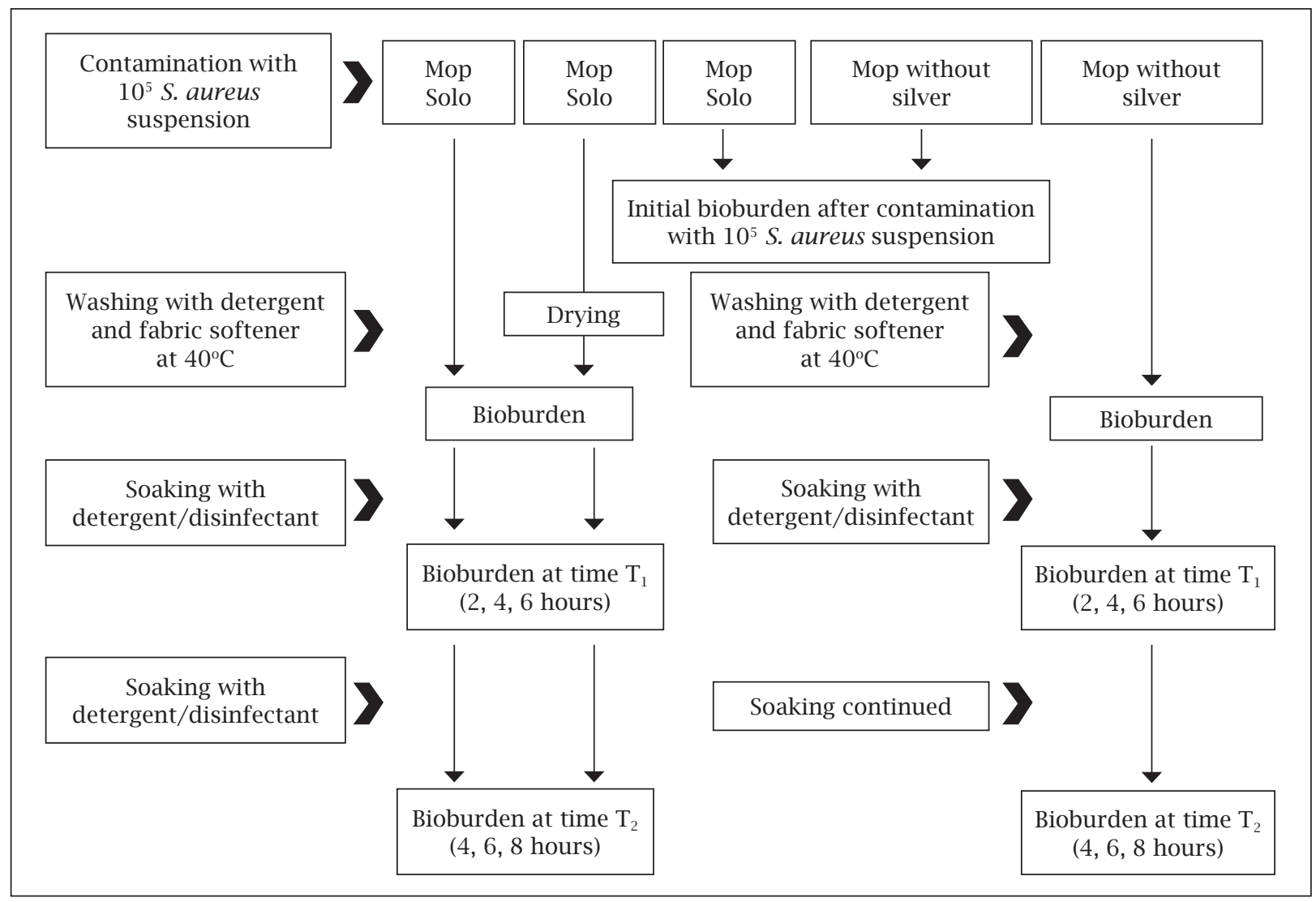

Figure 1: Flow chart of methods. 
disinfected by running a blank wash cycle. After washing at $40^{\circ} \mathrm{C}$ with a special detergent and fabric softener, one of the mops with the silver was machine dried and returned to the laboratory while the others (one with and one without silver) were returned to the laboratory still damp. The transport time was approximately one hour in a cooled container.

Two $50 \mathrm{~cm}^{2}$ samples were taken from each of the three mops and again tested to determine the bioburden after washing and, for one of the two mops with silver, after washing and drying.

In these cases, assuming that the washing process had reduced the microbial load, after agitation for $5 \mathrm{~min}$ with a mechanical rotary stirrer, the entire content was filtered on membranes (pore dimensions: $0.20 \mu \mathrm{m}$ ). After filtration of all the liquid, five washes were performed with $100 \mathrm{~mL}$ of sterile distilled water, the membranes were placed on the surface of Petri dishes containing Mannitol Salt Agar and incubated at $36.5 \pm 1^{\circ} \mathrm{C}$.

Thereafter, the remaining microfiber mop was set in a plastic container holding $200 \mathrm{~mL}$ of an alcohol-based detergent (Keradet Konzentrat-Aktiv) and left in place for 2, 4, 6 or 8 hours. Two additional $50 \mathrm{~cm}^{2}$ samples were taken after each of these impregnation times and tested as described above to determine the final bacterial load after different time duration in contact with the detergent. The Solo System mops with silver were only impregnated at the end of 2, 4, 6 or 8 hours and this was performed using an automatic water/detergent dispensing unit molded of a plastic with silver filaments and which supplied $200 \mathrm{~mL}$ doses of detergent.

In addition, at each step (2, 4, 6 or 8 hours), a $20 \mathrm{~mL}$ sample was taken of the detergent solution left in the Solo System soaking container and from the plastic container used to soak the microfiber mop without silver in order to evaluate any detergent contamination. Analysis was performed using the above-described process: filtering and washing through $0.20 \mu \mathrm{m}$ pore filtering membranes, depositing on Petri dishes with a suitable agar medium and incubation at $36.5 \pm 1^{\circ} \mathrm{C}$ for $24-48$ hours.

Finally, using a similar filtering procedure, $100 \mathrm{~mL}$ of the water/detergent solution from the Solo System container was tested to determine the bacterial load that may have developed by the end of the investigation.

\section{RESULTS}

A total of 10 trials were run - three at 2-4 hours, three at 2-6 hours, two at 4-8 hours and two at 6-8 hours. The initial bacterial load of the mops contaminated with 200 $\mathrm{mL}$ of a $10^{5}$ suspension of $S$. aureus was, on average, 1.47 x $10^{6} \pm 6.46 \times 10^{5}$ for the Solo mops made of microfiber with silver (range: $5.0 \times 10^{5}$ to $3.37 \times 10^{6}$ ) and $2.23 \times 10^{6} \pm$ $8.62 \times 10^{5}$ for the microfiber mops without silver (range: $7.90 \times 10^{5}$ to $4.24 \times 10^{6}$ ).

As shown in Table 1, even after a normal detergent wash at $40^{\circ} \mathrm{C}$, the bacterial load in the Solo mops - both damp and dry - was always completely nil. Instead, after washing, the microfiber mops without silver revealed a bacterial load of around $781.0 \pm 886.39 \mathrm{CFU} / 50 \mathrm{~cm}^{2}$. Between two and four hours after impregnation with the detergent/disinfectant, the bacterial load was reduced by an additional $50 \%$ to $339.70 \pm 286.74 \mathrm{CFU} / 50 \mathrm{~cm}^{2}$ after four hours; moreover, the same occurred after six and eight hours when the average 8-hour load was $168.63 \pm 76.50 \mathrm{CFU} / 50 \mathrm{~cm}^{2}$.

Regarding the $20 \mathrm{~mL}$ detergent samples taken at the end of each step, no detergent samples drawn from the Solo system containers with silver presented any bacterial growth; on the other hand, in four cases, the samples drawn from the plastic containers with the mops without silver did show signs of bacterial colony growth $(56,182$ and $5 \mathrm{CFU} / 20 \mathrm{~mL}$ after 2 hours and 13 CFU/20 mL after 6 hours). The $100 \mathrm{~mL}$ sample drawn at the end of the investigation from the Solo System container with silver did not show any signs of colony growth.

\section{CONCLUSIONS}

From the above results, it is clear that the Solo System microfiber mops containing silver ions are significantly more effective in reducing bacterial load, even in the presence of high experimentally applied $S$. aureus contamination $\left(10^{6}-10^{7} \mathrm{CFU} / 50 \mathrm{~cm}^{2}\right)$, than conventional microfiber mops without silver ions. Furthermore, this was the case no matter whether the mops were tested damp or dry. Indeed, after a low temperature wash, the bacterial load was already eradicated while the mops without silver ions showed relatively

Table 1. Averages and standard deviations in the number of cfu/50 $\mathrm{cm}^{2}$ of Staphylococcus aureus ATCC 6538 developed in the mops after wash cycles and 2, 4, 6 and 8 hours after onset of the tests

\begin{tabular}{lccccc}
\hline & $\begin{array}{c}\text { After wash } \\
\mathbf{1 0} \text { tests }\end{array}$ & $\begin{array}{c}\text { After } \mathbf{2} \text { hours } \\
\mathbf{6} \text { tests }\end{array}$ & $\begin{array}{c}\text { After } \mathbf{4} \text { hours } \\
\mathbf{5} \text { tests }\end{array}$ & $\begin{array}{c}\text { After } \mathbf{6} \text { hours } \\
\mathbf{5} \text { tests }\end{array}$ & $\begin{array}{c}\text { After } \mathbf{8} \text { hours } \\
\mathbf{4} \text { tests }\end{array}$ \\
\hline Mop in microfiber & $781.00 \pm 866.39$ & $365.33 \pm 222.14$ & $339.70 \pm 286.74$ & $141.30 \pm 83.96$ & $168.63 \pm 76.50$ \\
\hline Solo mop dried & $0.0 \pm 0.0$ & $0.0 \pm 0.0$ & $0.0 \pm 0.0$ & $0.0 \pm 0.0$ & $0.0 \pm 0.0$ \\
\hline Solo mop damp & $0.0 \pm 0.0$ & $0.0 \pm 0.0$ & $0.0 \pm 0.0$ & $0.0 \pm 0.0$ & $0.0 \pm 0.0$
\end{tabular}


high loads of the test microorganism (around $10^{2} \mathrm{CFU} /$ $50 \mathrm{~cm}^{2}$ ). When reused, such mops shall release its residual load to the treated surfaces.

Likewise, after soaking in a detergent/disinfectant, the mops without silver ions showed bacterial loads which were generally around $10^{2} \mathrm{CFU} / 50 \mathrm{~cm}^{2}$ even when soaked for as much as eight hours.

Moreover, the Solo System - composed of containers made of plastic with silver and where the tank and container used to soak the mop were separated and where the mop was only soaked in the detergent when it was about to be used - would appear effective in counteracting contamination of the detergent/disinfectant.

Finally, since the mops containing silver ions yielded complete decontamination even at low temperatures, use of such mops could produce real savings in terms of energy consumption for washing, and in terms of mop duration.

\section{REFERENCES}

1. Voss A, Verweij PE, Kluytmans J. Should we routinely disinfect floors? J Hosp Infect. 2003; 53(2):150.

2. Dettenkofer M, Spencer RC. Importance of environmental decontamination - a critical view. J Hosp Infect. 2007; 65(52):55-7.

3. Korn GP, Martino MDV, Mimica IM, Mimica LJ, Chiavone PA, de S. Musolino LR. High frequency of colonization and absence of identifiable risk factors for methicillin-resistant Staphylococcus aureus(MRSA) in intensive care units in Brazil. Braz J Infect Dis. 2001; 5(1):1-7.

4. Nilsen SK, Dahl I, Jørgensen O, Schneider T. Micro-fibre and ultra-micro-fibre cloths, their physical characteristics, cleaning effect, abrasion on surfaces, friction, and wear resistance. Building and Environment 2002; 37(12):1373-8.

5. Wren MWD, Rollins MSM, Jeanes A, Hall TJ, Coën PG, Gant VA. Removing bacteria from hospital surfaces: a laboratory comparison of ultramicrofibre and standard cloths. J Hosp Infect. 2008; 70(3):265-71.

6. More G, Griffith C. A laboratory evaluation of the decontamination proprieties of microfiber cloths. J Hosp Infect. 2006; 64(4):379-85.

7. Yeo SY, Jeong SH. Preparation and characterization of polypropylene/silver nanocomposite fibers. Polymer International 2003; 52(7):1053-7.

8. Mackeen PC, Person S, Warner SC, Snipes W, Stevens SE Jr. Silver-coated nylon fiber as an antibacterial agent. Antimicrob Agents Chemother. 1987; 31(1):93-9. 